\title{
Assessment of lower limb peripheral nerves with ultrasound in patients with traumatic amputation
}

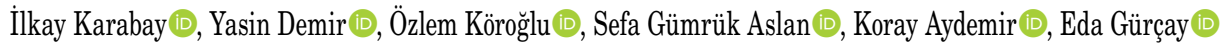 \\ Department of Physical Medicine and Rehabilitation, Health Sciences University, Gaziler Physical Therapy and Rehabilitation Training and Research Hospital, Ankara, Turkey
}

Received: December 15, 2020 Accepted: June 16, 2021 Published online: September 01, 2021

\begin{abstract}
Objectives: This study aims to assess the sciatic nerve (SN), common peroneal nerve (CPN), and tibial nerve (TN) by ultrasound in patients with traumatic lower limb amputation (LLA) and to examine the possible relationship between ultrasonographic and clinical findings.

Patients and methods: This cross-sectional study included a total of 33 male patients (mean age: $36.6 \pm 8.7$ years; range, 21 to 48 years) who had LLA due to traumatic injury between May 2019 and April 2020. Amputation and prosthesis use and functional K level of activity were recorded. Ultrasound examinations were performed to measure the cross-sectional areas (CSAs) of the SN, CPN, and TN bilaterally at the same levels. The values from the normal sides were accepted as controls.

Results: The CSA values were greater on the amputated sides than the non-amputated sides for SN ( $p=0.001), T N(p=0.001)$, and CPN $(\mathrm{p}=0.015)$, regardless of the activity level. The amputated side SN $(\mathrm{p}=0.001)$, TN $(\mathrm{p}=0.001)$, and CPN ( $\mathrm{p}=0.016)$ were thicker in patients with level of K4 activity than the non-amputated side. For the patients with K3 activity level, larger TN CSA values were determined on the amputated side, compared to those at the K4 level $(\mathrm{p}=0.035)$. The $\mathrm{SN}$ was found to be greater in patients using microprocessor-controlled knee prosthesis $(\mathrm{p}=0.032)$ and TN was larger in hypobaric sealing membrane users on the amputated sides $(\mathrm{p}=0.041)$.

Conclusion: The SN, CPN, and TN were found to be larger in all patients on the amputated sides and in patients with K4 activity level. Based on these findings, the K3 activity level and the use of hypobaric sealing membrane seems to affect the CSA values of TN. Additionally, the use of microprocessor knee prosthesis affects the CSA values of SN. We believe that these results may be essential for the analysis or prediction of lower extremity nerve involvement according to the K activity level and the use of prosthesis in patients with traumatic LLA.
\end{abstract}

Keywords: Activity level, amputation, lower limb, peripheral nerve, ultrasound.

Lower limb amputation (LLA) commonly affects young and active individuals who have a long life expectancy. It is a major surgery causing many functional deficiencies which can impair overall health quality and physical condition of the patients and necessitating a multidisciplinary rehabilitation program. ${ }^{[1]}$ Pain, psychological illness, insulin resistance, blood hypercoagulability, and metabolic syndrome are the most frequent drawbacks after LLA. $^{[2]}$

High-frequency ultrasonography is useful in the evaluation of peripheral nerves, as it has many advantages over other techniques. It has high resolution and does not contain ionizing radiation. In addition, dynamic and real-time visualization is possible. ${ }^{[3]}$ Ultrasound has been shown to have the same specificity and sensitivity as magnetic resonance imaging in assessing peripheral nerves. ${ }^{[4]}$

In the literature, there are studies evaluating peripheral nerves in entrapment disorders, immunemediated neuropathies, traumatic injuries, and neuromuscular disorders. ${ }^{[5]}$ The cross-sectional area (CSA) of a peripheral nerve is the most accepted parametric quantity as a reference for the size of

\footnotetext{
Corresponding author: İlkay Karabay, MD. SBÜ Gaziler Fizik Tedavi ve Rehabilitasyon Eğitim ve Araştırma Hastanesi, Fizik Tedavi ve Rehabilitasyon Kliniği, 06800 Çankaya, Ankara, Türkiye. e-mail: ilkaykarabay@gmail.com 
a peripheral nerve, and increased CSA evaluates pathology. Sonographic imaging of the sciatic nerve (SN) after LLA due to malignant causes has been presented..$^{[6]}$ The $\mathrm{SN}$ has been also examined in patients with LLA $^{[7]}$ and unilateral sciatica ${ }^{[8]}$ using ultrasound to determine whether ultrasonographic findings are related to clinical characteristics.

However, there is no study in the literature investigating the CSA of the $\mathrm{SN}$, common peroneal nerve $(\mathrm{CPN})$, and tibial nerve (TN) sonographically combined with functional activity levels reflecting the clinical condition of patients with traumatic LLA. In the present study, we, therefore, aimed to assess the SN, $\mathrm{CPN}$, and TN by ultrasound in patients with traumatic LLA and to examine the possible relationship between ultrasonographic and clinical findings.

\section{PATIENTS AND METHODS}

This cross-sectional study was conducted at Health Sciences University, Gaziler Physical Therapy and Rehabilitation Training and Research Hospital, Department of Physical Medicine and Rehabilitation between May 2019 and April 2020. A total of 33 male patients (mean age: $36.6 \pm 8.7$ years; range, 21 to 48 years) who had LLA due to traumatic injury and were followed in the amputee clinic were included. All patients had completed stump healing. Those with any disease affecting the peripheral nerves (e.g., diabetes mellitus, infections, metabolic problems, inherited causes, and exposure to toxins) were excluded. A written informed consent was obtained from each patient. The study protocol was approved by the Health Sciences University, Gülhane Education and Research Hospital Ethics Committee (May 14, 2019/19-198). The study was conducted in accordance with the principles of the Declaration of Helsinki. Demographic and clinical characteristics of the participants including age, sex, amputation findings (etiology, time since amputation, level, and side), prosthesis use findings (time since prosthesis use, daily use time, type, type of liner, prosthetic foot type), and functional $\mathrm{K}$ level of activity after amputation were recorded. The $\mathrm{K}$ levels are mostly used to classify the type of ambulation. The level ranges from 0 to 4 , where 0 refers to the patient who does not have the ability or potential to ambulate or transfer safely, with or without assistance, and a prosthesis does not enhance their quality of life or mobility, and level 4 has the ability or potential for prosthetic ambulation that exceeds basic ambulation skills, exhibiting high impact, stress, or energy levels.
The presence, etiology, and duration of pain were questioned, and the intensity of pain was assessed by Visual Analog Scale (VAS). The Leeds Assessment of Neuropathic Symptoms and Signs (LANSS) was used to evaluate neuropathic pain for the residual limb. The patient's satisfaction with the current prosthesis was evaluated numerically between 0 (not satisfied at all) and 10 (completely satisfied).

All ultrasonographic examinations were performed by a single physiatrist experienced in musculoskeletal sonography. A 5 to $12 \mathrm{MHz}$ linear transducer (Logiq E portable; GE Healthcare, China) was used. To optimize image quality, minimal pressure was applied to the transducer. Each examination was performed bilaterally while the patients were in the prone position. The full course of the $\mathrm{SN}, \mathrm{TN}$, and CPN was assessed in a craniocaudal direction starting from the subgluteal fold to the popliteal fossa. The probe was placed axially on the nerves (perpendicular to the nerve) and the CSA was measured at the same level proximal to the bifurcation for the SN (Figure 1), and at a point distal to the bifurcation of the SN for the CPN and TN (Figure 2). The values from the normal sides were accepted as controls. The presence of a neuroma was also evaluated throughout the nerve, particularly at the distal ends.

As previously described by Kara et al., ${ }^{[8]}$ when the mean CSA of the SN was accepted as $43.3 \pm 12.5 \mathrm{~mm}^{2}$, the power of the study was calculated as $80 \%$ with a type-1 error of 0.05 . Accordingly, a total of 34 patients were planned to be recruited.

\section{Statistical analysis}

Statistical analysis was performed using the SPSS for Windows version 16.0 (SPSS Inc., Chicago, IL, USA). Continuous variables were expressed in mean \pm standard deviation (SD) or median (min-max). Categorical variables were expressed in number and frequency. The Kolmogorov-Smirnov test was used to confirm that the data showing normal distribution. The Student t-test and Wilcoxon tests were performed to compare SN, CPN and TN CSA values between amputated versus non-amputated sides, $\mathrm{K} 3$ versus $\mathrm{K} 4$ level activity, microprocessorcontrolled knee prosthesis versus other types, and hypobaric sealing membrane versus silicone liners. The Spearman correlation was used to examine the relationship between demographic, clinical, and ultrasound parameters. A $p$ value of $<0.05$ was considered statistically significant. 

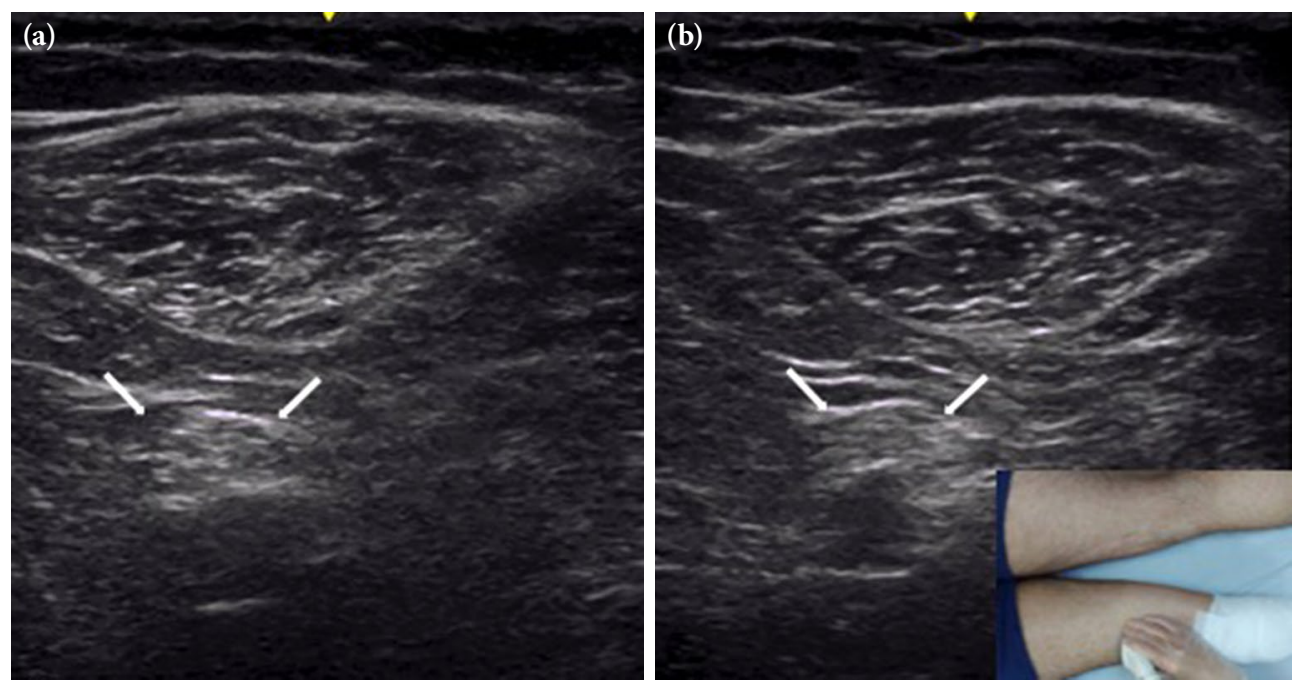

Figure 1. Axial sonographic images obtained from the proximal level of bifurcation of sciatic nerve. (a) White arrows indicate hyperechoic oval-shaped sciatic nerves under thigh muscles. (b) The sciatic nerve appears wider and thicker on the amputated side than on the normal side. Small figure at the bottom right illustrates the probe position.

\section{RESULTS}

Demographic and clinical characteristics of the patients are summarized in Table 1. Sixteen patients reported pain in the amputated extremities. The mean

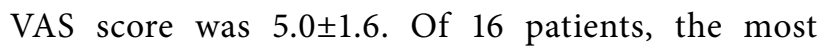
common causes of pain were neuropathic $(n=6)$ and prosthetic use-related pain $(n=5)$. The mean LANSS score for neuropathic pain was $16 \pm 4.3$.
The CSA values were greater on the amputated sides than the non-amputated sides for $\mathrm{SN}(\mathrm{p}=0.001), \mathrm{TN}$ $(\mathrm{p}=0.001)$, and CPN $(\mathrm{p}=0.015)$, regardless of activity level. Similarly, the amputated side $\mathrm{SN}(\mathrm{p}=0.001)$, $\mathrm{TN}(\mathrm{p}=0.001)$, and CPN $(\mathrm{p}=0.016)$ were thicker than the non-amputated side in patients with level of K4 activity. There was no significant difference in CSA values between amputated and non-amputated sides in K3 level patients (Table 2).
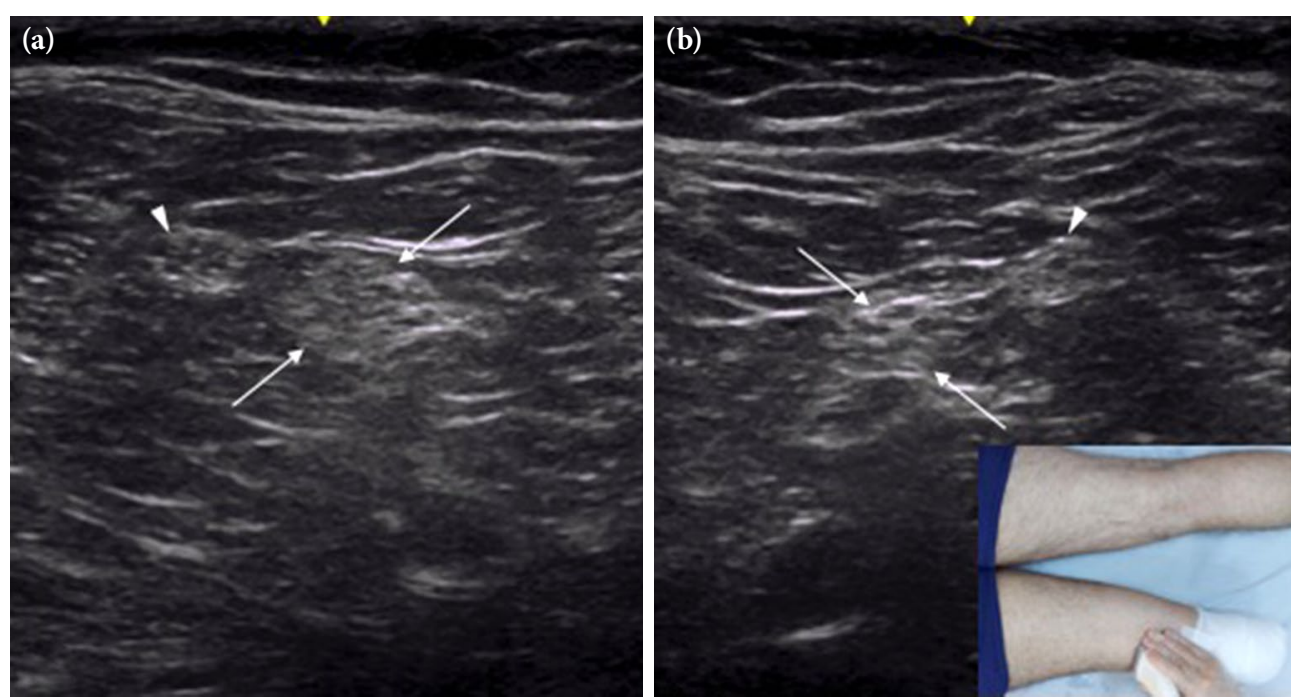

Figure 2. Axial sonographic images obtained from the distal level of bifurcation of sciatic nerve. The tibial nerves (arrows) and common peroneal (arrowheads) nerves are visualized in hyperechoic oval-shape. (a) The nerves appear wider and thicker on the amputated side than on the normal side. (b) Small figure at the bottom right illustrates the probe position. 


\begin{tabular}{|c|c|c|c|c|c|}
\hline \multicolumn{6}{|c|}{$\begin{array}{l}\text { TABLE } 1 \\
\text { Demographic and clinical characteristics of patients }(n=33)\end{array}$} \\
\hline & $\mathrm{n}$ & $\%$ & Mean \pm SD & Median & Min-Max \\
\hline Age (year) & & & $36.6 \pm 8.7$ & & \\
\hline Time since amputation (month) & & & & 132 & $5-360$ \\
\hline Time since prosthesis use (month) & & & & 123.9 & $1-360$ \\
\hline Daily prosthesis use time (h) & & & & 10.6 & $1-19$ \\
\hline \multicolumn{6}{|l|}{ Etiology of amputation } \\
\hline Mine & 15 & 45.5 & & & \\
\hline Hand-made explosive & 8 & 24.2 & & & \\
\hline Gun & 5 & 15.2 & & & \\
\hline Rocket & 2 & 6.1 & & & \\
\hline Traffic accident & 2 & 6.1 & & & \\
\hline Other & 1 & 3.0 & & & \\
\hline \multicolumn{6}{|l|}{ Side of amputation } \\
\hline Right & 16 & 48.5 & & & \\
\hline Left & 17 & 51.5 & & & \\
\hline \multicolumn{6}{|l|}{ Level of amputation } \\
\hline Above knee & 7 & 20.6 & & & \\
\hline Knee disarticulation & 3 & 8.8 & & & \\
\hline Below knee & 20 & 58.8 & & & \\
\hline Chopart & 4 & 11.8 & & & \\
\hline \multicolumn{6}{|l|}{ Type of prosthesis } \\
\hline Microprocessor-controlled knee prosthesis & 9 & 27.3 & & & \\
\hline Hydrolic knee prosthesis & 1 & 3.0 & & & \\
\hline Active vacuum system modular below-knee prosthesis & 18 & 54.5 & & & \\
\hline Passive vacuum system modular below-knee prosthesis & 1 & 3.0 & & & \\
\hline Chopart prosthesis & 4 & 12.1 & & & \\
\hline \multicolumn{6}{|l|}{ Type of liner } \\
\hline Hypobaric sealing membrane & 18 & 54.5 & & & \\
\hline Silicone liner & 11 & 33.3 & & & \\
\hline \multicolumn{6}{|l|}{ Prosthetic Foot } \\
\hline Carbon & 21 & 63.6 & & & \\
\hline Hydrolic & 8 & 24.2 & & & \\
\hline Chopart & 4 & 12.1 & & & \\
\hline Satisfaction with prosthesis & & & $7.0 \pm 2.8$ & & \\
\hline \multicolumn{6}{|l|}{ Activity level } \\
\hline K3 & 3 & 9.1 & & & \\
\hline K4 & 30 & 90.9 & & & \\
\hline
\end{tabular}

\section{TABLE 2}

Comparisons of the CSA values of nerves on amputated and non-amputated sides

\begin{tabular}{|c|c|c|c|c|c|c|c|c|c|}
\hline & \multicolumn{3}{|c|}{ All patients } & \multicolumn{3}{|c|}{ K3 level } & \multicolumn{3}{|c|}{ K4 level } \\
\hline & $\begin{array}{l}\text { Non-amputated } \\
\text { side }\end{array}$ & $\begin{array}{l}\text { Amputated } \\
\text { side }\end{array}$ & & $\begin{array}{l}\text { Non-amputated } \\
\text { side }\end{array}$ & $\begin{array}{l}\text { Amputated } \\
\text { side }\end{array}$ & & $\begin{array}{l}\text { Non-amputated } \\
\text { side }\end{array}$ & $\begin{array}{l}\text { Amputated } \\
\text { side }\end{array}$ & \\
\hline & Mean \pm SD & Mean \pm SD & $p$ & Mean \pm SD & Mean \pm SD & $p$ & Mean \pm SD & Mean \pm SD & $p$ \\
\hline Sciatic nerve $\left(\mathrm{mm}^{2}\right)$ & $49.5 \pm 7.1$ & $53.1 \pm 7.0$ & 0.001 & $53.3 \pm 3.1$ & $58.3 \pm 1.2$ & 0.109 & $49.2 \pm 7.4$ & $52.6 \pm 7.2$ & 0.001 \\
\hline Common peroneal nerve $\left(\mathrm{mm}^{2}\right)$ & $17.5 \pm 3.5$ & $18.6 \pm 3.5$ & 0.015 & $17.6 \pm 2.1$ & $16.5 \pm 0.7$ & 1.0 & $17.5 \pm 3.6$ & $18.8 \pm 3.7$ & 0.016 \\
\hline Tibial nerve $\left(\mathrm{mm}^{2}\right)$ & $25.8 \pm 3.9$ & $27.6 \pm 3.6$ & 0.001 & $28.6 \pm 1.5$ & $32.5 \pm 0.7$ & 0.180 & $25.5 \pm 4.0$ & $27.3 \pm 3.5$ & 0.001 \\
\hline
\end{tabular}




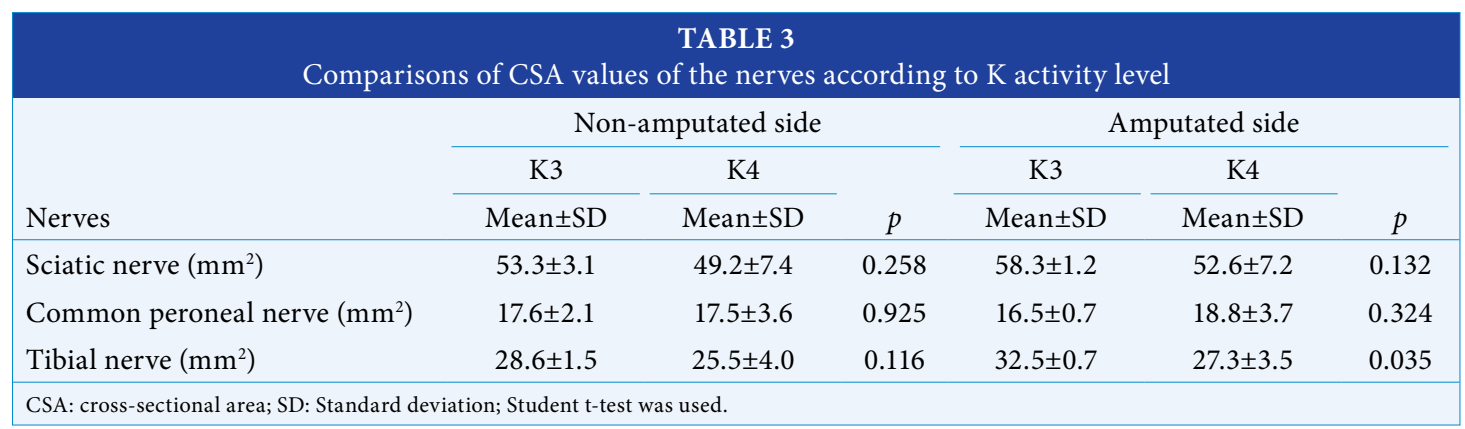

\begin{tabular}{|c|c|c|c|c|c|c|}
\hline \multirow[b]{4}{*}{ Nerves } & \multirow{2}{*}{\multicolumn{2}{|c|}{$\begin{array}{l}\text { TABI } \\
\text { etween patients using } n \\
\text { Non-amputated side }\end{array}$}} & \multirow[b]{4}{*}{$p$} & \multirow{2}{*}{\multicolumn{2}{|c|}{ Amputated side }} & \multirow[b]{4}{*}{$p$} \\
\hline & & & & & & \\
\hline & Micropressor-controlled & Other & & \multirow{2}{*}{$\frac{\text { Micropressor-controlled }}{\text { Mean } \pm \text { SD }}$} & \multirow{2}{*}{$\begin{array}{c}\text { Other } \\
\text { Mean } \pm \text { SD }\end{array}$} & \\
\hline & Mean \pm SD & Mean \pm SD & & & & \\
\hline Sciatic nerve $\left(\mathrm{mm}^{2}\right)$ & $51.8 \pm 5.2$ & $48.6 \pm 7.6$ & 0.240 & $57.2 \pm 5.5$ & $51.6 \pm 7.0$ & 0.032 \\
\hline Common peroneal nerve $\left(\mathrm{mm}^{2}\right)$ & $17.4 \pm 2.8$ & $17.5 \pm 3.7$ & 0.984 & $19.2 \pm 3.2$ & $18.6 \pm 3.7$ & 0.630 \\
\hline Tibial nerve $\left(\mathrm{mm}^{2}\right)$ & $27.1 \pm 3.7$ & $25.3 \pm 3.9$ & 0.239 & $30.4 \pm 4.0$ & $27.1 \pm 3.3$ & 0.124 \\
\hline
\end{tabular}

According to the activity level, only the mean values of TN CSA were higher in the amputated side in patients with $\mathrm{K} 3$ activity level compared to those at the K4 level (32.5 \pm 0.7 vs. $27.3 \pm 3.5$, respectively) $(\mathrm{p}=0.035)$ (Table 3$)$.

When the CSA values of the nerves were compared according to types of prosthesis and liner, the amputated side $\mathrm{SN}$ was found to be thicker in patients using microprocessor-controlled knee prosthesis $(\mathrm{p}=0.032)$ (Table 4$)$. The TN was greater in hypobaric sealing membrane users on the amputated sides (30.0 $\pm 3.6 v s .26 .5 \pm 3.2$, respectively) $(\mathrm{p}=0.041)$.

The correlation analyses for demographic and clinical parameters including age, sex, amputation etiology, time since amputation, level, and side, time since prosthesis use, daily use time, type, type of liner, prosthetic foot type, activity level and ultrasound findings revealed only a negative mild correlation $(\mathrm{r}=-0.415, \mathrm{p}<0.05)$ with the CSA values of the TN on the amputated sides and daily prosthesis use time.

\section{DISCUSSION}

The present study results clearly demonstrated that the CSA of the SN, CPN, and the TN were larger on the amputated sides in all patients. Furthermore, we observed that the $\mathrm{SN}$ was found greater in patients using microprocessor-controlled knee prosthesis and $\mathrm{TN}$ was greater in hypobaric sealing membrane users on the amputated sides. We also identified a slightly negative correlation between the CSA values of TN on the amputated sides and the duration of daily prosthesis use.

Axotomy in peripheral nerves leads to reduced demyelination and atrophy in neurofilaments and eventually loss of motor neurons. After nerve transection, distal axons undergo Wallerian degeneration, while proximal axons undergo functional and morphological changes called axon reaction or retrograde effect. ${ }^{[9]}$ In an animal experiment, permanent axotomy resulted in axonal atrophy in adult cats, but axonal development continued in kittens but never reached to adult size. ${ }^{[10]}$ Kerimoğlu and Canyigit ${ }^{[11]}$ who conducted research on nerve diameter found $\mathrm{SN}$ hypertrophy on amputated side not only in the young patient, but also in the adult patient, consistent with the results of Hill et al. ${ }^{[6]}$ in case series involving seven patients with osteosarcoma under the age of 19. There are some animal experiments showing that local application of insulin-like growth factor-I (IGF-I) to the SN stimulates regeneration. ${ }^{[12-14]}$ It was thought that trophic factors such as IGF-I and cytokines secreted by osteosarcoma could be the cause of hypertrophy, but still the etiology has not been fully elucidated, yet. In these two studies, the nerve diameters increased in a direct proportion to the amputation time, and 
the reason for this increase could be the longer exposure to trophic factors secreted by sarcomas. ${ }^{[6,11]}$ In our study, no significant correlation was found between the amputation time and the CSA values of the nerves. This can be attributed to the fact that all patients were traumatic amputees and not exposed to trophic factors.

Peripheral nerve measurements can be helpful in monitoring and preventing problems, such as neuroma that we often see in amputees in rehabilitation clinics. Göktepe et al. ${ }^{[7]}$ examined the thickness and width of the SN nerve in patients with LLA and found that the $\mathrm{SN}$ on the amputated side was wider and thicker, and was also thicker in above-knee amputees than in below-knee amputees. They showed that amputation level and duration and presence of neuroma affected the nerve diameter. Therefore, it is thought that the underlying pathogenesis of $\mathrm{SN}$ enlargement (proximal) and neuroma formation (distal) may have common determinants However, no neuroma samples were found in our study.

In the nervous system, some substances are transported from the center to the periphery and from the periphery to the center. In antegrade transport, all the substances that the axon needs for survival and function are produced in the nerve cell body and transported from the axon to the periphery. These axonal transport substances in neurons include proteins, neurotransmitters, lipids, mitochondria and ribonucleic acid (RNA). ${ }^{[15,16]}$ The function of retrograde transport is the recycling of materials initially transported from the cell body to the axon terminals, as well as the transfer of information to the center by neuro-trophic factors about the axon status, terminals, target cells and general environment. ${ }^{[16,17]}$ Impingement or axotomy in peripheral nerves may affect the circulation of the nerve root and the metabolism of neurotransmitters flowing in the axons by disrupting the axonal flow, resulting in neural edema and, therefore, the amount of endoneural tissue increases and the size of the nerve may eventually grow. ${ }^{[18]}$ In our study, the increase in all CSAs on the amputated side indicates the increase in endoneural tissue as a result of the interruption of axonal transport.

Since we believe that the prosthesis and its components may affect the peripheral nerve diameter in amputees, we found it necessary to investigate all these parameters. The prostheses used by amputees have many components. Socket and liner are important parts of prosthesis due to their interfaces between stump and socket. ${ }^{[19-23]}$ Liner is in direct contact with the stump in the socket and plays an important role in transferring the load and distributing the interface pressure over the stump. ${ }^{[24,25]}$ A comfortable liner and socket are important for patients using prosthesis to avoid skin problems in their daily activities. ${ }^{[25,26]}$ Recently, it has been shown that superior quality liners provide better suspension, are more comfortable and cause less dermatological problems than previous prosthetic designs. ${ }^{[27,28]}$ While the silicone liner suspension is based on the shuttle lock system, the hypobaric sealing membrane has five seals around the liner and the socket inner wall that form an airtight seal for proper suspension. Silicone liners adhere to the patient's stump, strengthening the contact surface with the socket and providing a comfortable cushion between the prosthetic socket and the stump. Sadeeq Ali et al. ${ }^{[28]}$ compared the satisfaction level in patients using pelite liner, silicone liner and hypobaric sealing membrane and showed a higher level of satisfaction with silicone liner. A higher level of disappointment, pain, and skin irritation were observed in patients using hypobaric sealing membrane liners. Since the seals in hypobaric sealing membrane liners have the potential to exert additional pressure on the stump, they can be a source of trouble for amputees with sensitive stumps. In another study supporting this concept, it was attempted to measure and evaluate the interface pressure in silicone and hypobaric sealing membrane liners during normal walking. While walking on a flat surface of both liners, the interface pressure in the anterior, posterior, medial and lateral regions was measured. As a result, all pressure measurements of the hypobaric sealing membrane liner were found to be higher than the silicone liner. The silicon liner has been shown to provide greater comfort in the socket than a hypobaric sealing membrane. ${ }^{[20]}$ In our study, a comparison was made between the liner types in terms of the CSA of the nerves. The CSA values of the TN on the amputated side were greater in users of hypobaric sealing membrane compared to silicone liner users. The reasons for this were considered as the seals applying more pressure on the stump and the vacuum effect resulting in more recurrent skin problems and trauma effect in hypobaric sealing membrane liner users.

The CSA values of the SN were found to be larger in patients using microprocessor prostheses compared to other prosthesis users. We believe that it is caused by edema formation due to the high burden on the amputated limb, as the microprocessor prostheses are heavier and the patients who use them are more 
active, this may affect the CSA values. To the best of our knowledge, there is no study on this subject in the literature.

Many studies have shown that ultrasonographic measurement is a useful diagnostic tool for evaluating nerve disorders. ${ }^{[6-8,11]}$ Ultrasonography provides clear information about the anatomy and morphology of structures. In this context, it is a guide while revealing the treatment plan or prognosis. ${ }^{[29]}$ For instance, in the presence of an intraneural ganglion cyst requiring surgical procedure, ultrasonography alone detects the etiology that cannot be determined by electrophysiological study, leading to a more accurate prognosis. ${ }^{[30]}$ As a result, peripheral nerve measurements and follow-up of these parameters may contribute to clinicians' tracking and selection of the most accurate prosthesis and prosthetic parts. Additionally, peripheral nerve measurements are helpful to analyze and predict lower extremity nerve involvement according to the $\mathrm{K}$ activity level.

The main limitations of this study are its small sample size and heterogeneous patient distribution according to the $\mathrm{K}$ activity levels. However, the main strengths include the evaluation of the prosthesis and liner types clinically, examination of the $\mathrm{K}$ activity levels functionally, and scanning of three nerves together sonographically.

In conclusion, the $\mathrm{SN}$, the $\mathrm{TN}$, and the $\mathrm{CPN}$ were found to be larger in all patients on the amputated sides and in patients with $\mathrm{K} 4$ activity level. Based on these findings, the $\mathrm{K} 3$ activity level and the use of hypobaric sealing membrane seem to affect the CSA values of the TN. Additionally the use of microprocessor knee prosthesis affects the CSA values of the $\mathrm{SN}$. We consider that these results may be essential for the analysis or prediction of lower extremity nerve involvement according to the $\mathrm{K}$ activity level and the use of prosthesis in patients with traumatic LLA.

\section{Declaration of conflicting interests}

The authors declared no conflicts of interest with respect to the authorship and/or publication of this article.

\section{Funding}

The authors received no financial support for the research and/or authorship of this article.

\section{REFERENCES}

1. Perkins ZB, De'Ath HD, Sharp G, Tai NR. Factors affecting outcome after traumatic limb amputation. Br J Surg 2012;99 Suppl 1:75-86.
2. Köroğlu Ö, Tel Adigüzel K. Cardiometabolic risk parameters of individuals with lower extremity amputation: What is the effect of adherence to DASH diet and Mediterranean diet? Turk J Phys Med Rehabil 2020;66:291-8.

3. Sikdar S, Wei Q, Cortes N. Dynamic ultrasound imaging applications to quantify musculoskeletal function. Exerc Sport Sci Rev 2014;42:126-35.

4. Padua L, Hobson-Webb LD. Ultrasound as the first choice for peripheral nerve imaging? Neurology 2013;80:1626-7.

5. Klauser AS, Peetrons P. Developments in musculoskeletal ultrasound and clinical applications. Skeletal Radiol 2010;39:1061-71.

6. Hill SC, Baker AR, Barton NW, Wexler LH, Scott LJ. Sciatic nerve: Paradoxic hypertrophy after amputation in young patients. Radiology 1997;205:559-62.

7. Göktepe AS, Ozçakar L, Kömürcü E, Safaz I, Yazicioğlu K. Sonographic evaluation of the sciatic nerve in patients with lower-limb amputations. Muscle Nerve 2010;41:763-6.

8. Kara M, Özçakar L, Tiftik T, Kaymak B, Özel S, Akkuş $S$, et al. Sonographic evaluation of sciatic nerves in patients with unilateral sciatica. Arch Phys Med Rehabil 2012;93:1598-602.

9. Dyck PJ, Lais A, Karnes J, Sparks M, Dyck PJ. Peripheral axotomy induces neurofilament decrease, atrophy, demyelination and degeneration of root and fasciculus gracilis fibers. Brain Res 1985;340:19-36.

10. Jorgensen D, Dyck PJ. Axonal underdevelopment from axotomy in kittens. J Neuropathol Exp Neurol 1979;38:571-8.

11. Kerimoglu U, Canyigit M. Paradoxic hypertrophy of the sciatic nerve in adult patients after above-knee amputation. Acta Radiol 2007;48:1028-31.

12. Emel E, Ergün SS, Kotan D, Gürsoy EB, Parman Y, Zengin A, et al. Effects of insulin-like growth factor-I and plateletrich plasma on sciatic nerve crush injury in a rat model. J Neurosurg 2011;114:522-8.

13. Rabinovsky ED. The multifunctional role of IGF-1 in peripheral nerve regeneration. Neurol Res 2004;26:204-10.

14. Aloe L, Rocco ML, Bianchi P, Manni L. Nerve growth factor: From the early discoveries to the potential clinical use. J Transl Med 2012;10:239.

15. Grafstein B, Forman DS. Intracellular transport in neurons. Physiol Rev 1980;60:1167-283.

16. Perlson E, Maday S, Fu MM, Moughamian AJ, Holzbaur EL. Retrograde axonal transport: Pathways to cell death? Trends Neurosci 2010;33:335-44.

17. Menorca RM, Fussell TS, Elfar JC. Nerve physiology: Mechanisms of injury and recovery. Hand Clin 2013;29:317-30.

18. Kobayashi S, Kokubo Y, Uchida K, Yayama T, Takeno K, Negoro K, et al. Effect of lumbar nerve disc compression on primary sensory neurons and their central branches: changes in the nociceptive neuropeptides substance $\mathrm{P}$ and somatostatin. Spine (Phila Pa 1976) 2005;30:276-82.

19. Jia X, Zhang M, Lee WC. Load transfer mechanics between trans-tibial prosthetic socket and residual limb--dynamic effects. J Biomech 2004;37:1371-7. 
20. Ali S, Osman NA, Mortaza N, Eshraghi A, Gholizadeh $\mathrm{H}$, Wan Abas WA. Clinical investigation of the interface pressure in the trans-tibial socket with Dermo and SealIn $\mathrm{X} 5$ liner during walking and their effect on patient satisfaction. Clin Biomech (Bristol, Avon) 2012;27:943-8.

21. Goh JC, Lee PV, Chong SY. Comparative study between patellar-tendon-bearing and pressure cast prosthetic sockets. J Rehabil Res Dev 2004;41:491-501.

22. Coleman KL, Boone DA, Laing LS, Mathews DE, Smith DG. Quantification of prosthetic outcomes: Elastomeric gel liner with locking pin suspension versus polyethylene foam liner with neoprene sleeve suspension. J Rehabil Res Dev 2004;41:591-602.

23. Lin CC, Chang CH, Wu CL, Chung KC, Liao IC. Effects of liner stiffness for trans-tibial prosthesis: A finite element contact model. Med Eng Phys 2004;26:1-9.

24. Dou P, Jia X, Suo S, Wang R, Zhang M. Pressure distribution at the stump/socket interface in transtibial amputees during walking on stairs, slope and non-flat road. Clin Biomech (Bristol, Avon) 2006;21:1067-73.

25. Hall M, Shurr D, VanBeek M, Zimmerman M. The Prevalence of dermatological problems for transtibial amputees using a roll-on liner. JPO Journal of Prosthetics and Orthotics 2008;20:134-9.

26. Baars EC, Geertzen JH. Literature review of the possible advantages of silicon liner socket use in trans-tibial prostheses. Prosthet Orthot Int 2005;29:27-37.

27. Gallagher P, MacLachlan M. Development and psychometric evaluation of the trinity amputation and prosthesis experience scales (TAPES). Rehabilitation Psychology 2000;45:130-54.

28. Ali S, Abu Osman NA, Arifin N, Gholizadeh H, Abd Razak NA, Abas WA. Comparative study between Dermo, Pelite, and Seal-In X5 liners: Effect on patient's satisfaction and perceived problems. ScientificWorldJournal 2014;2014:769810.

29. Kim JY, Song S, Park HJ, Rhee WI, Won SJ. Diagnostic cutoff value for ultrasonography of the common fibular neuropathy at the fibular head. Ann Rehabil Med 2016;40:1057-63.

30. Visser LH. High-resolution sonography of the common peroneal nerve: Detection of intraneural ganglia. Neurology 2006;67:1473-5. 